\title{
A Review and Algorithm in the Diagnosis and Treatment of Sacroiliac Joint Pain
}

This article was published in the following Dove Press journal:

Journal of Pain Research

\author{
Steven Falowski (iD) \\ Dawood Sayed (1D ${ }^{2}$ \\ Jason Pope ${ }^{3}$ \\ Denis Patterson ${ }^{4}$ \\ Michael Fishman (1D ${ }^{5}$ \\ Mayank Gupta ${ }^{6}$ \\ Pankaj Mehta ${ }^{7}$
}

'Neurosurgical Associates of Lancaster, Lancaster, PA I760I, USA; ${ }^{2}$ University of Kansas, Kansas City, KS, USA; ${ }^{3}$ Evolve Restorative Center, Santa Rosa, CA, USA; ${ }^{4}$ Nevada Advanced Pain Specialists, Reno, NV, USA; ${ }^{5}$ Center for Interventional Pain and Spine, Lancaster, PA, USA; ${ }^{6}$ Kansas Pain Management, Overland Park, KS, USA; ${ }^{7}$ Pain Specialists of America, Austin, TX, USA
Correspondence: Steven Falowski Neurosurgical Associates of Lancaster, 160 N Pointe Blvd \#200, Lancaster, PA I760I, USA

Tel +l 717-358-0800

Email sfalowski@gmail.com
Introduction: The sacroiliac joint (SIJ) has been estimated to contribute to pain in as much as $38 \%$ of cases of lower back pain. There are no clear diagnostic or treatment pathways. This article seeks to establish a clearer pathway and algorithm for treating patients.

Methods: The literature was reviewed in order to review the biomechanics, as well as establish the various diagnostic and treatment options. Diagnostic factors addressed include etiology, history, physical exam, and imaging studies. Treatment options reviewed include conservative measures, as well as interventional and surgical options.

Results: Proposed criteria for diagnosis of sacroiliac joint dysfunction can include pain in the area of the sacroiliac joint, reproducible pain with provocative maneuvers, and pain relief with a local anesthetic injection into the SIJ. Conventional non-surgical therapies such as medications, physical therapy, radiofrequency denervation, and direct SI joint injections may have some limited durability in therapeutic benefit. Surgical fixation can be by a lateral or posterior/posterior oblique approach with the literature supporting minimally invasive options for improving pain and function and maintaining a low adverse event profile.

Conclusion: SIJ pain is felt to be an underdiagnosed and undertreated element of LBP. There is an emerging disconnect between the growing incidence of diagnosed SI pathology and underwhelming treatment efficacy of medical treatment. This has led to an increase in SI joint fixation. We have created a clearer diagnostic and treatment pathway to establish an algorithm for patients that can include conservative measures and interventional techniques once the diagnosis is identified.

Keywords: sacroiliac joint, SIJ pain, sacroiliac joint dysfunction, sacroiliitis, sacroiliac joint fusion

\section{Introduction}

Low back pain (LBP) is among the most common human health problems, with a global point prevalence of $9.4 \%$, yearly prevalence of $38 \%$, and accounting for half of years lived with disability (YLD) due to a musculoskeletal disorder worldwide. ${ }^{1}$ Chronic low back pain (cLBP) is a complex biopsychosocial condition in which recurrent back pain with or without clear pathology leads to chronic pain, physical dysfunction, social isolation, and/or mood changes. ${ }^{2}$ It is challenging to treat a nonspecific condition and even more difficult to treat symptoms without an accurate diagnosis to allow for source control.

The sacroiliac joint (SIJ) is a large, irregularly shaped, serpentine joint structure bordered anteriorly and posteriorly by the sacroiliac ligaments. The joint itself is about two-thirds synovial and one-third ligamentous, with the synovial portion extending anteroinferiorly and reinforced at its posterosuperior aspect by syndesmotic ligament. ${ }^{3}$ 
The form of the SIJ begets its function - it is intended for stability, with a sacral concave depression interlocking with a corresponding iliac osseous ridge. ${ }^{3}$ This construct is further reinforced extra-articularly by the sacrospinous and sacrotuberous ligaments. The SIJ complex is part of the kinetic chain connecting the spine and lower extremities, and may be a primary or secondary pain generator depending on the clinical scenario and should be examined routinely in the evaluation of back or leg complaints. The SIJ is particularly enigmatic in its ability to mimic hip and lumbar spine pathology and also to result from the surgical treatment of hip and spine issues. Yoshihara proposes that misdiagnosed sacroiliac syndrome occurs commonly, such that some patients may undergo unnecessary lumbar fusion. ${ }^{4}$ This highlights the importance of educating clinicians on the SIJ, as the treatment option landscape has evolved to become significantly less invasive, and the accurate diagnosis and treatment of LBP is paramount.

The SIJ has been estimated in a number of series to contribute to pain in $10-38 \%$ of cases of $\mathrm{LBP}^{4-7}$ The early and accurate diagnosis and treatment of LBP is critical to mitigating conversion to CLBP and high-impact pain states that are managed as chronic disease. The purpose of this article is to review the diagnostic and treatment algorithm for symptomatic SIJ dysfunction in the patient presenting with low back pain.

\section{Presentation}

\section{Sacroiliac Joint Biomechanics}

The SI joints are designed primarily for stability. The joint rotates about three planes of axes (flexion and extension, rotation, and translation) but by very small amounts approximated at two degrees. Motion along the sacroiliac joint is not linear as it occurs simultaneously in multiple planes. Anatomic pathology changes affecting many of the SI joint structures can lead to nociception. There are numerous reported etiologies for SI joint pain. The causes can be divided into intraarticular and extra-articular sources. Examples of intraarticular causes are arthritis and infection of the SI joint. Common extra-articular causes include enthesopathy, fractures, ligamentous injury, and myofascial pain. In addition to the etiologic sources, there are numerous factors that can predispose a person to gradually develop SI joint pain. Risk factors that increase stress on the SI joint are leg length discrepancy, ${ }^{8}$ gait abnormalities, ${ }^{9}$ prolonged vigorous exercise, ${ }^{10}$ scoliosis, ${ }^{11}$ pregnancy, ${ }^{12,13}$ spinal fusion to the sacrum, ${ }^{14}$ and hip pathology. ${ }^{15,16}$

\section{History Findings}

The sacroiliac joint can be responsible for $10-38 \%$ of low back pain, ${ }^{4-6}$ and oftentimes presents with pain below the belt line with radiations into the groin and lower extremity, infrequently with radiations below the knee in the L5-S1 dermatomal pattern. ${ }^{17}$ The pain is aching in quality, with absence of burning quality or numbness and tingling. ${ }^{18}$ Pain is often with movement, can radiate into the ipsilateral groin and into the buttock. ${ }^{19}$ The differential of evaluation of low back can be narrowed by the performance of a physical exam and performance of provocative maneuvers for the diagnosis of sacroiliac joint pain.

\section{Diagnostic Criteria}

Increasing the difficulty of diagnosis is the poor sensitivity with imaging. X-rays, computed tomography, and magnetic resonance may offer some indication for abnormalities, but may not be specific alone. ${ }^{20}$ The joint is difficult to profile well on radiographic views, and therefore the radiographic findings of sacroiliitis are often equivocal. MRI is the most sensitive imaging technique to detect sacroiliitis. It is the only imaging modality that can reliably reveal bone marrow edema and inflammation around the sacroiliac joints and is comparable to low dose CT for demonstrating erosions and ankyloses. ${ }^{21}$

Three hundred and seventy-eight patients were retrospectively identified who underwent definitive diagnostic injections with different sources of low back pain. The mean age and the number of patients reporting hip girdle pain, leg pain, and thigh pain were determined in each diagnostic group. This explored the relationship between predictors and the source of LBP. Age correlates with the source of low back pain, as disc disease is more likely in the younger population and older patients are likely to have diagnosis of sacroiliac or facetogenic pain. Interestingly, the absence of thigh pain in older patients increases the likelihood of sacroiliac joint dysfunction as a source of low back pain. ${ }^{22}$

\section{Physical Exam Findings}

Telli et al looked at the validity and reliability of provocation tests in the diagnosis of sacroiliac joint dysfunction in 156 patients, investigating the distraction test, compression test, Gaenslen test, thigh thrust test, sacral thrust test, and Faber test. Diagnosis was made with three or more positive provocation tests, ${ }^{19}$ with the highest sensitivity being Faber (91.4\%) and lowest probability was Gaenslen test. 


\section{Description of Provocation Maneuvers Provocative Testing}

The five following provocative tests have a high degree of sensitivity and specificity when used in combination. Three or more tests must be positive with at least one resulting from the Thigh Trust or Compression Test. This diagnostic threshold yields a sensitivity of $85 \%$ and a specificity of $76 \% .{ }^{17}$ Testing sequence ought to be performed in a manner to minimize position changes for patient comfort and may include tests to diagnose comorbid hip pathology.

\section{The Distraction Test}

The patient lies supine with the examiner standing next to the patient at or just inferior to the level of the pelvis. Examiner will place each palm on the patient's ASIS while keeping elbows extended and apply an adequate posterolateral force directed at distracting the SI joints. The test is positive when the patient's pain is reproduced.

\section{Thigh Thrust Test}

With the patient still supine and examiner standing on the patient's affected side, position the ipsilateral leg to 90degree hip flexion and allow the knee to passively flex. The examiner places one hand on contralateral ASIS to stabilize the pelvis. The opposite hand is then placed on the anterior aspect of the passively flexed knee and vertical pressure is applied posteriorly through the patient's femur to create a shearing force at the affected SI joint. The test is positive when the patient's pain is reproduced.

\section{FABER Test}

While the patient remains supine, position the affected leg to 90-degree hip and knee flexion. Abduct and externally rotation the ipsilateral leg at the hip joint and rest the lateral aspect of the patient's calf on the anterior aspect of the contralateral thigh, resembling a figure four. The examiner places one hand on the contralateral ASIS to stabilize the pelvis. The opposite hand applies a gentle posteriorly directed force on the anteromedial aspect of the affected side knee. This test is positive for SI joint pain when the patient describes posteriorly localized pain near the affected side SI joint and can fulfill the three or more requirement for provocation testing. However, if the pain is described anteriorly this may indicate hip pathology as the sole or an additional source of pain contributing to the patient's presentation. At this point, addition hip special testing (i.e., Scour Test, FADIR Test) can be performed.

\section{Compression Test}

If the examiner must continue provocative testing to adequately evaluate the SI joint, the patient is asked to lie on the unaffected side with the suspected SI joint facing upward and both hips and knees comfortable flexed. Examiner will stand posterior to the patient at the level of the pelvis. The examiner places one palm between the upward-facing ASIS and greater trochanter and uses the free hand to brace the contacted hand. With the examiner's elbows fully extended, vertical pressure is applied through the pelvis into the exam table. The test is positive when the patient's pain is reproduced.

\section{Gaenslen's Maneuver}

Provocation testing is continued with the patient positioned back to supine and the affected side pelvis laterally displaced toward the edge of the exam table. The patient is asked to maximally flex the unaffected side hip and knee and hold that position using their hands. The examiner will then drape the affected side leg over the side of the examination table moving the hip into an extended position. The examiner will stabilize the flexed extremity with one hand while simultaneously provided gentle downward pressure on the anterior aspect of the extended thigh. The test is positive when the patient's pain is reproduced.

\section{Common Etiologies and Risk Factors}

Sacroiliac joint dysfunction and the common etiologies to consider are best identified by an appreciation for the anatomy. With the sacroiliac joint largely being innervated by L4-S3 for nociception, along with intra and extraarticular sources of dysfunction: muscular irritation, capsular disruption, shearing, fractures, infection, and arthritis. ${ }^{18}$ These etiologies can be acute or repetitive in nature. ${ }^{23}$ Historic risk factors and associations include scoliosis, lumbar fusion, pregnancy, seronegative HLAB27 spondyloarthropathies, repetitive athletic activity, and leg length discrepancies. ${ }^{18}$ Hyperparathyroidism and repetitive shear-stress injuries in athletes can cause sacroiliitis-like changes of the joint. ${ }^{24}$

Perhaps the two most common risk factors for developing SIJ dysfunction are history of pregnancy and history of a prior lumbar surgery. The joint can become painful during pregnancy as it widens and develops increased motion. This can lead to further pathology overtime. It has also been shown that multilevel lumbar surgery and fusion may yield higher incidence of SIJ pain as compared to discectomy alone. ${ }^{25}$ 


\section{Proposed Criteria for Diagnosis}

The International Association for the Study of Pain (IASP) proposed criteria for diagnosis of sacroiliac joint dysfunction. ${ }^{23}$ Diagnosis is described as pain in the area of the sacroiliac joint (approximately $3 \mathrm{~cm} \mathrm{x} 10 \mathrm{~cm}$ inferior to the ipsilateral posterior superior iliac spine, ${ }^{26}$ reproducible with provocative maneuvers, and must be relieved with local anesthetic injection into the SIJ or the lateral branch nerves, although this is controversial. Fluoroscopic guided intraarticular injection with either local anesthetic with an addition (or not) of a corticosteroid is helpful in diagnosis and treatment, although periarticular injections have also been advocated for. ${ }^{27}$ Interestingly, for those patients that did well with surgical treatment, the response to an intraarticular local anesthetic injection of $75 \%$ relief or greater of at least 30-60 minutes in duration was consistent. ${ }^{28,29}$ Cohen et al investigated 77 patients with refractory SIJ pain in two academic institutions in a multivariate analysis. ${ }^{30}$ Pre-procedure pain intensity, age older than 65 years, and pain radiating below the knee were significant predictors of failure. Lateral branch pulsed RF versus intraarticular steroid injections were investigated in randomized, prospective manner, suggesting that pulsed RF of the dorsal rami and the S1-3 lateral branch nerves provided more durable relief and functional improvement, suggesting lateral branch nerve intervention can diagnosis and manage sacroiliac joint dysfunction. ${ }^{31}$

\section{Non-Surgical Treatment Options}

Chronic Sacroiliac Joint Pain (CSJP) as a result of sacroiliac pathology has historically been difficult to diagnose based on clinical signs and symptoms, however, recent studies have shown that image-guided injection of a local anesthetic is the gold standard for diagnosing SIJ pain. ${ }^{23,28,29,31}$ Although having a more defined pathway for diagnosis has become helpful, the treatment algorithm is less clear. Treatment options include conventional medical management, conservative modalities such as focused Physical Therapy (PT), less invasive interventions such as nerve blocks and neuroablations, and surgical stabilization or SIJ fusion.

\section{Conventional Medical Management}

If there is no correctable etiology identified in a painful sacroiliac joint (SIJ), simple analgesics may be considered as the initial therapy as part of the multidisciplinary approach. There are no studies specifically regarding pharmacologic management of painful SIJ, but data extrapolated from management of non-neuropathic chronic low back pain have suggested that muscle relaxants and NSAIDs may be effective as initial regimens to target the myofascial and the inflammatory component of the pain presentation. ${ }^{32}$ Any escalation to the strength of analgesics should be guided by the $\mathrm{WHO}$ analgesic ladder.

\section{Physical Therapy}

Exercise is particularly beneficial in patients with a painful SIJ. ${ }^{33}$ Reduced laxity of SIJ has been linked to contraction of the transverse abdominus muscle fibers suggesting that isolated contraction of a transversely oriented musculature such as pelvic floor muscles or piriformis could stabilize the joint hence reducing pain during activities. ${ }^{34}$ In a small comparative study, symptomatic patients demonstrated myoelectric hyperactivity of the ipsilateral gluteus muscles and contralateral latissimus muscle compared to the asymptomatic control group. ${ }^{35}$ The myoelectric activity returned to normalcy after a 10week intense PT. This reciprocal relationship of the latissimus dorsi on one side and the gluteus maximus on the other side is well understood and forms a key component of the strength exercise program.

\section{Diagnostic and Therapeutic Injections}

An analgesic response to an SI joint injection is the most accurate means to diagnose a painful SI joint complex. ${ }^{36}$ The specificity of a subjective response to a low volume of local anesthetic (generally accepted volume based on the joint space) has always been in question. ${ }^{37}$ Multiple studies have looked at the therapeutic effect of SIJ injections - a few have demonstrated significant benefit but being small powered studies the authors were not able to demonstrate statistically significant differences in medication usage or functionality between the treatment and control groups. ${ }^{38-40}$ Of the ones which evaluated periarticular injections with corticosteroids, patients continued to have good pain relief at 6 months demonstrating decreased spontaneous pain, provoked pain, and tenderness. A recent review of 15 publications related to spondylarthritis showed that a good response was reported in more than $80 \%$ of the cases, with a mean duration of improvement over 8 months. ${ }^{41}$ Eighty-five percent of the subjects reviewed from other observational studies also obtained significant pain relief lasting for an average of 10 months. $^{42-45}$ Diagnostic or therapeutic injections should be performed using the aid of fluoroscopy, as 
studies have shown that only $22 \%$ of non-radiologically guided SI injections extended into the joint space. ${ }^{46}$

\section{Neuroablative Techniques}

If conservative and SIJ therapeutic injections have failed to provide relief neuro-ablative techniques are an accepted next best step to manage a painful SIJ. The posterior sensory innervation of the SIJ is through nerve branches that pass medially from the posterior aspect of the SIJ to converge to the rami dorsalis from the L4 to the S1-S4 dorsal rami. Given these anatomic features, different SIJ RF ablation approaches have been described:

1. Sequential Radiofrequency lesions in the posteroinferior aspect of the joint by leapfrogging an electrode at less than $1-\mathrm{cm}$ intervals. ${ }^{47}$ However, a review of this technique pointed out that only $36 \%$ of patients reported more than $50 \%$ pain relief lasting at least 6 months, being that only a small portion of the joint was denervated.

2. Intra-articular phenol has been suggested by some in the past, but because of the inherent risks most practicing physicians who treat SIJ pain shy away from this method of ablation. ${ }^{48}$

3. RF ablation targeting the lateral branches of the primary dorsal rami from L5-S2 has met with more auspicious results, with most studies reporting sustained relief lasting at least 6 months in over $60 \%$ of subjects. ${ }^{49-52}$ Anatomic studies have demonstrated that the lateral branches which provide nociceptive and proprioceptive input from the SI joints vary in number, location, level and also between patients, ${ }^{51}$ hence conventional RF techniques where the RF lesion is about 3-4 $\mathrm{mm}$ and uniplanar cannot capture it all.

4. Enhancing lesion size to overcome this obstacle, has been attempted using bipolar lesioning, internally cooled electrodes, and replacing RF electrodes with cryoprobes. ${ }^{53,54}$ Bipolar lesioning has yielded good anecdotal results by creating a continuous strip lesion, the technique itself is limited by wide variations in tissue impedance around the sacral foramina resulting in asymmetric ablative patterns.

5. Cryoablation has also led to a shorter duration of benefit. ${ }^{53,54}$

6. Both controlled and uncontrolled studies support the use of cooled RF. In a randomized, placebocontrolled study $64 \%$ and $57 \%$ of patients experienced more than $50 \%$ pain relief at 3- and 6-month follow-up, respectively, with comparable improvements in function and medication reduction the median duration of benefit in successful patients being 8 months. ${ }^{52,53}$

7. Lateral sacral neuro-ablation by the above techniques may not benefit all painful SIJ pain because targeting the posterior nerve supply of the joint does not address pain emanating from the ventral aspect of the joint. One study ${ }^{55}$ found that lateral sacral branch blocks were more effective at preventing SIJ pain secondary to extra-articular (i.e., ligamentous) stimulation than from capsular distension. Another analyzed 77 patients and concluded that more than half of the patients continue to experience at least $50 \%$ relief greater than 6 months post procedure with predictors like the elderly, higher preprocedure pain scores, opioid usage, and pain radiating beyond the knee were associated with treatment failure. $^{30}$

8. Internally cooled electrodes remove the constraint of tissue charring on lesion expansion; hence, it can increase lesion diameter by $200 \%$ to $300 \%$, and volume by a factor of 8 thus eliminating the concern of lesion size during thermal radiofrequency.

The nerve supply of the SIJ complex has been described posteriorly by the lateral branches of the S1-S3 dorsal rami (with some fibers of the L4 and L5 dorsal rami) while the anterior aspect is supplied by branches of the lumbosacral trunk and the obturator and superior gluteal nerves. ${ }^{56}$ Limited success with percutaneous radiofrequency ablation has been attributed to not just the course variability of the innervating nerves, but also that innervation of the joint complex is very variable. ${ }^{57,58}$ Being that the anterior and posterior compartments of the SIJ joint complex have their own individual varying nerve supply, radiofrequency neurotomy of the posterior nerves may not provide complete relief of the painful presentation.

\section{Neuromodulation}

During the past few decades, spinal cord and peripheral nerve stimulation have increasingly been used to treat chronic pain and recent studies have shown that subcutaneous stimulation and sacral nerve root stimulation may be successful in treating SIJ pain and coccygodynia, respectively. ${ }^{59,60}$ However, more studies are needed for neuromodulation to be a primary therapy for painful SIJ syndromes. 


\section{Surgical Treatment Options}

\section{Timing of Intervention}

Surgical stabilization and/or fusion of the sacroiliac joint should be considered when a patient has persistent moderate to severe pain, functional impairment, and failed a minimum of 6 months of intensive non-operative care. Surgical stabilization and/or fusion can be done by two approaches: 1) lateral approach and/or 2) posterior and posterior oblique approach. These approaches are described below. The medical literature has shown that minimally invasive surgical treatment for the sacroiliac joint can improve pain and increase function. ${ }^{29,61-70} \mathrm{It}$ should be noted that the current medical literature supports the lateral approach as there are limited studies that support the posterior and posterior lateral oblique approach.

\section{Lateral Approach}

The lateral approach to sacroiliac fusion as currently practiced was originally introduced in 2008 with the FDA 510 (k) approval for the first minimally invasive (MIS) lateral approach (iFuse Implant System, SI Bone). Many other systems have come to market since that time with various modifications and differentiators to the iFuse System. Currently, there are 14 different lateral SI fusion systems on the market. ${ }^{71}$ Prior to the MIS lateral approach, SI fusion was performed by an open Smith-Peterson approach, first described in $1921 .^{72}$ Although this approach proved effective, this open approach was associated with complications of blood loss, tissue stripping, and extended recovery times. ${ }^{3}$ Minimally invasive lateral approaches largely have replaced open approaches over the past 10 years, with approximately $85 \%$ of SI fusions being performed via this technique. ${ }^{73}$ Lateral approaches are generally performed by surgeons.

\section{Surgical Technique: Lateral Approach}

Although a complete description of surgical technique is beyond the scope of this manuscript, Minimally Invasive Surgical (MIS) lateral approach SI fusion is typically performed under general anesthesia and under fluoroscopic guidance. Due to risk of neurological damage to the lumbosacral nerve roots, intraoperative neuromonitoring may be utilized. ${ }^{74}$ Depending on the specific system, guidewires are typically placed at the superior, middle, and inferior aspects of the sacroiliac joint. Dilating cannula are inserted prior to drilling over the guidewire to the intended endpoint. Most systems then utilize titanium screws packed with allograft to promote arthrodesis.

\section{Safety}

MIS lateral SI fusion has shown improved safety over the traditional open approach, including lower surgical complication rates and lower incidence of non-union. ${ }^{68}$ Several post-surgical complications are still prevalent with MIS lateral approach. Complication rates as high as $16.4 \%$ have been reported in the literature. ${ }^{75}$ Most complications reported are non-emergent such as increased hip, back, and buttock pain, and hematoma. Although more serious adverse events such as deep wound infection, and nerve root impingement have been reported. ${ }^{76} \mathrm{~A}$ systematic review of lateral MIS fusion was performed by Shamrock et al in 2019. Fourteen studies were included. The review reported an overall complication rate of $11.1 \%$, with the most common being wound infection $(n=17 / 819,2 \%)$. Nerve root impingement was reported in $1.6 \%$ of cases $(13 / 819){ }^{77}$

\section{Efficacy}

Evidence for the MIS lateral approach has been positive for efficacy in reducing back pain and improving functional outcomes. A level I two-year randomized controlled study comparing an MIS lateral approach to conservative management revealed a superior improvement in back pain and Oswestry Disability Index (ODI) with the lateral surgical approach. The surgical arm had an improvement of 55.4 points compared to 12.2 on a 100-point VAS scale. Additionally, $68 \%$ of patients had a greater than 15-point improvement in ODI at 24 months compared to $7.5 \%$ in the conservative arm. ${ }^{29}$ Martin et al published a comprehensive review of the current literature for lateral MIS Sacroiliac fusion. In this review, they provided a pooled analysis of all existing data. The pooled analysis showed a mean decrease of 80.3 to 32.2 on a 100 -point VAS scale additionally they also reported a mean decrease in ODI of 56.2 to 34.4 . A Limitation of this review is that the majority of the data is retrospective and mainly where involving the iFuse Implant system. $^{78}$

\section{Posterior and Posterior Oblique Approach}

Recent minimally invasive surgical techniques have been described to stabilize the sacroiliac joint from a posterior and posterior oblique approach. These surgical techniques 
stabilize the sacroiliac joint by either placing 1-3 surgical screws across the joint or by placing 1-2 percutaneous cortical allografts along the joint. Posterior and posterior oblique approaches are presently performed by surgeons or interventional pain physicians.

\section{Surgical Screw Fixation}

The patient should be placed in a prone position on a radiolucent operating room table. Using fluoroscopy, the c-arm is positioned in a sacral outlet view to approximate the posterior sacral iliac spine (PSIS) between the $\mathrm{S} 1$ and S2 foramen where the implants will best be accommodated. A PAK Needle is then placed just lateral to the PSIS and pointed toward the sacral promontory. The PAK needle is then advanced through the ilium, across the sacroiliac joint, and into the sacrum. The inner stylet from the PAK Needle is then removed and a guidewire is inserted until it is $1 \mathrm{~cm}$ from the anterior sacral cortex. The PAK Needle is removed while leaving the guidewire in place. A drill is then advanced over the guidewire until the depth stop makes contact with the ilium. A tap instrument is then advanced over the guidewire until its depth stop makes contact with the ilium. The guidewire is then removed. The threaded implant is advanced through the prepared channel until the implant head is flush with the ilium. The above steps are then repeated to place up to three implants at the surgeon's discretion.

\section{Percutaneous Graft Placement}

The patient should be placed in a prone position on a radiolucent table (flattop or Jackson table) on chest rolls, which will allow the hips to have 15-20 degrees of hip flexion to level off the pelvis. Using fluoroscopy, the c-arm should be rotated in a medial to lateral oblique orientation (15-20 degrees) until the posterior and anterior sacroiliac joint lines become superimposed. A Steinman pin or pins is/are then placed into sacroiliac joint. If one percutaneous cortical allograft is being placed, the Steinman pin will be placed in the middle third of the sacroiliac joint. If two percutaneous cortical allografts are being placed, then one Steinman pin is being placed in the inferior third of the sacroiliac joint while the second Steinman pin is placed in the superior third of the sacroiliac joint. The two pins should be in intersecting planes at 70-90 degrees to each in the A-P plan (as seen from a lateral fluoroscopic view). Once the Steinman pin(s) is/ are in place, a joint finder or dilatator is advanced over the Steinman pin(s) until it is fully seated into the sacroiliac joint. A guide retraction tube or second dilator is then advanced over the top of the joint finder/Steinman pin(s) until the feet of the guide retraction tube is in line with the joint space. The joint finder/Steinman pin(s) are then removed while leaving the guide retraction tube in place. The sacroiliac joint is then decorticated by using a joint decorticator and/or surgical drill through the guide retraction tube. A broach is then advanced down the guide retraction tube to prepare the graft site for the cortical graft. Demineralized Bone Matrix (DBM) and the cortical allograft(s) are then placed along the sacroiliac joint using an inserter and final impactor. Once the graft is in place, the inserter, final impactor, and guide retraction tube are removed.

\section{Discussion}

Low back pain (LBP) is among the most common human health problems and accounts for a significant amount of disability worldwide. ${ }^{1}$ It is a challenging condition to diagnose and treat given its unclear pathology, multifactorial causes, biopsychosocial aspects, and poorly defined treatment algorithms. Interestingly, the SIJ has been estimated to contribute to pain in as much as $38 \%$ of cases of LBP. $^{4-6,17}$ Given these findings, it is felt that SIJ pain is highly underdiagnosed and also undertreated. ${ }^{79}$ In addition, there is no clear diagnostic or treatment pathway once identified. In this article, we reviewed the diagnostic criteria and treatment options to begin to establish a clearer pathway and algorithm for patients.

Patients generally present with pain below the belt line or isolated over the SIJ. Radiation can be most commonly into the posterior leg, groin, or buttock. There is usually an absence of thigh pain, especially in older patients. In addition to SI joint dysfunction, clinicians should be aware of broader differential diagnosis in regards to other possible sources of posterior hip and lower back pain. In addition to other common spinal pathologies such as the lower facet joints and lumbar discs, other pathologies such as tarlov cysts, pudendal nerve entrapments, hamstring tendinopathies, and piriformis syndrome should also be considered. ${ }^{80}$ Additionally in female patients, intrapelvic sources such as endometriosis and pelvic varicosities should be considered. ${ }^{81}$ The sacroiliac joint is also affected by the lack of movement in the hip joint. Hip abnormalities limiting flexion can cause increased strain on sacroiliac joint, ${ }^{16}$ while limitation in hip extension is also reported by some authors in association with low back pain. ${ }^{82,83}$ 
The two most common risk factors are history of pregnancy and history of prior lumbar surgery, ${ }^{25}$ but can also include scoliosis and repetitive athletic injuries among others. Physical exam findings are based on provocative maneuvers in which criteria usually calls for three or more being positive. These include distraction test, compression test, Gaenslen test, thigh thrust test, sacral thrust test, and Faber test. There is poor sensitivity with imaging, especially x-rays, but in general CT and MRI can be sensitive for detecting inflammation and/or arthritic type changes.

The IASP proposed criteria for diagnosis of sacroiliac joint dysfunction ${ }^{23}$ which includes pain in the area of the sacroiliac joint, reproducible with provocative maneuvers, and must be relieved with local anesthetic injection into the SIJ or the lateral branch nerves. Although the need for diagnostic and/or therapeutic injection has become

\section{SACROILIAC JOINT DYSFUNCTION ALGORITHM FOR THE INTERVENTIONALIST}

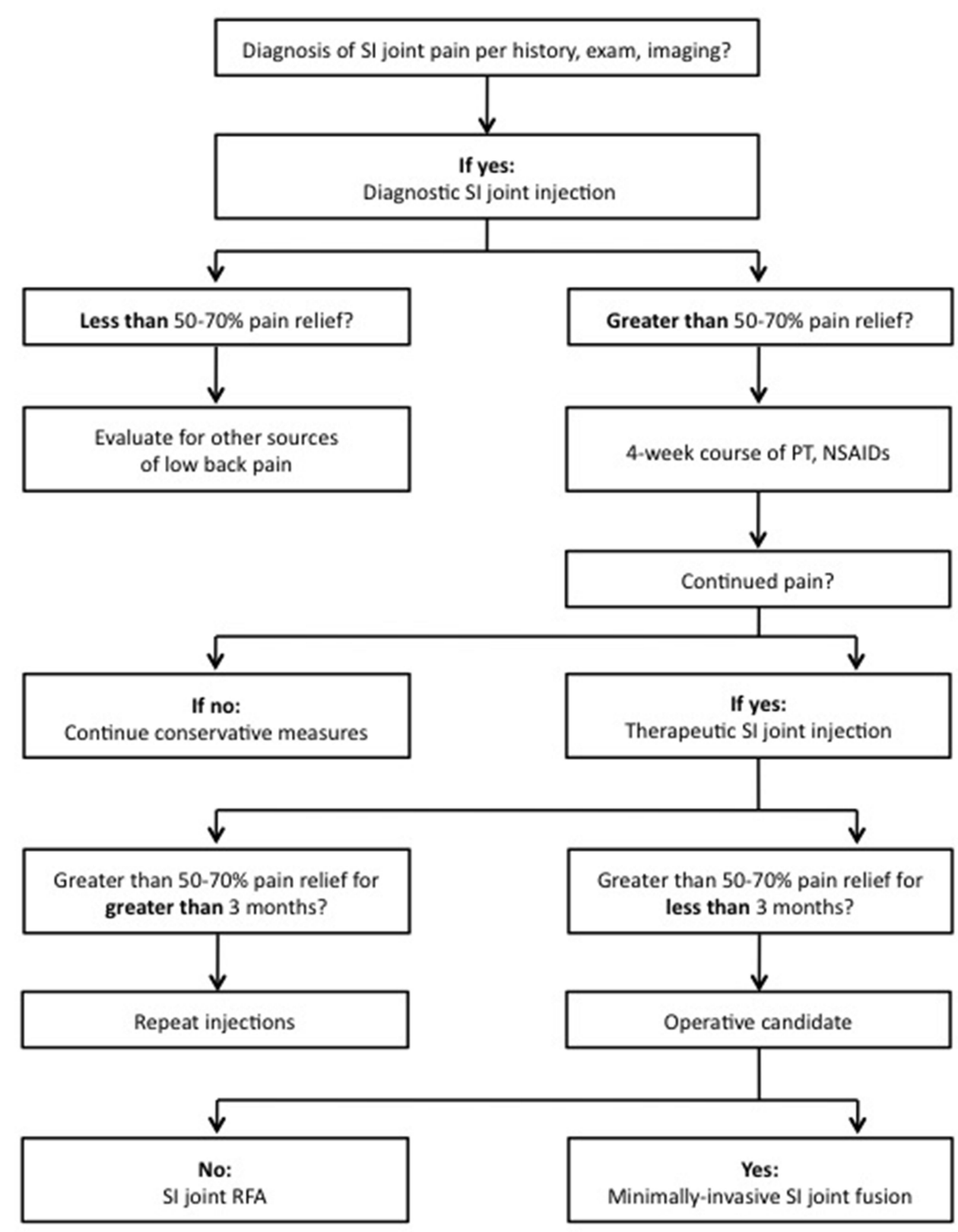

Figure I Algorithmic approach to SI joint pain. 
controversial, it is generally accepted to be helpful in diagnosis and treatment.

Conventional non-surgical therapies such as oral analgesic use, physical therapy, chiropractic treatment, radiofrequency denervation, and direct SI joint injections have been relied on as frontline therapies. However, they have shown limited durability in therapeutic benefit. It is generally accepted to start with conservative measures such as NSAIDs, muscle relaxants, and physical therapy. An SIJ injection whether diagnostic or therapeutic can also be considered as part of both the early diagnostic and treatment algorithm and may yield more clarity for patient identification for further treatment options if conservative measures fail. Figure 1 presents an algorithmic approach to the diagnosis and management of SI joint pain. It accounts for the use of conservative measures, diagnostic and therapeutic injections, as well as surgery and RFA. Some insurance carriers will require $70 \%$ pain relief with injections prior to proceeding with a surgical fixation. In addition, some carriers also require two injections prior to fixation which can be covered by having both a diagnostic and therapeutic injection.

The emerging disconnect between the growing incidence of diagnosed SI pathology and underwhelming treatment efficacy of medical treatment has been matched with an increase in surgical SI joint fusion procedures for intractable SI joint pain. Rather than managing inflammation and pain, surgical fusion of the SI joint immobilizes the joint and eliminates the motion thought to cause inflammation and SI joint pain. Surgical stabilization of the sacroiliac joint is generally considered when a patient has persistent moderate to severe pain, functional impairment, and failed a minimum of 6 months of conservative care. Surgical fixation can be by a lateral or posterior/ posterior oblique approach with the literature supporting minimally invasive options for improving pain and function and maintaining a low adverse event profile. The majority of the literature supports the lateral approach being the most studied. The posterior/posterior oblique approaches, as well as percutaneous graft implants over hardware, have opened a pathway for interventional pain physicians to now offer these therapies in lieu of a surgeon.

\section{Conclusion}

SIJ pain is felt to be an underdiagnosed and undertreated element of LBP. We sought to create a clearer diagnostic and treatment pathway to establish an algorithm for patients that can include conservative measures and interventional techniques once the diagnosis is identified.

\section{Author Contributions}

All authors made substantial contributions to conception and design, acquisition of data, or analysis and interpretation of data; took part in drafting the article or revising it critically for important intellectual content; agreed to submit to the current journal; gave final approval of the version to be published; and agree to be accountable for all aspects of the work.

\section{Funding}

There were no funding sources for this article.

\section{Disclosure}

Steven Falowski consults for Abbott, Medtronic, Boston Scientific, Vertoss and Saluda; research is performed with Abbott, Boston Scientific, Medtronic, Biotronik, Saluda, Stimgenics and Vertiflex; Equity positions held in Saluda, CornerLoc, Painteq, Celeri, SPR Therapeutics, Thermaquil, Stimgenics, SpineThera, Neural Integrative Solutions, and AGR; and is the owner of Neural Integrative Solutions, outside the submitted work. Dawood Sayed reports personal fees from Flowonix, Medtronic, Merit, Nevro, Vertiflex and Vertos,and stock options in PainTeq, SPR, and Vertos.Jason Pope reports stock options for Painteq, outside the submitted work. Denis Patterson reports personal fees from CornerLoc, outside the submitted work. Michael Fishman reports personal fees from Foundation Fusion Solutions, outside the submitted work. Mayank Gupta reports personal fees from Nevro Corp., speakers bureau/consultant/investigator for Vertos, Inc., advisory/medical board/consultant/investigator for Avertias Pharma, consultant/investigator for US WorldMeds, Nalu Medical, and SPR Therapeutics, Inc., and consultant/medical board for Foundation Fusion Solutions, LLC (CornerLoc), during the conduct of the study. Pankaj Mehta reports consultant for ABBOTT, BOSTON SCIENTIFIC, SPR, CORNER LOC, and ETHOS LABS, outside the submitted work. The authors report no other potential conflicts of interest for this work.

\section{References}

1. March L, Smith EUR, Hoy DG, et al. Burden of disability due to musculoskeletal (MSK) disorders. Best Pract Res Clin Rheumatol. 2014;28(3):353-366. doi:10.1016/j.berh.2014.08.002 
2. Deyo RA, Dworkin SF, Amtmann D, et al. Report of the NIH task force on research standards for chronic low back pain. $J$ Pain. 2014;15(6):569-585. doi:10.1016/j.jpain.2014.03.005

3. Tsoi C, Griffith JF, Lee RKL, Wong PCH, Tam LS. Imaging of sacroiliitis: current status, limitations and pitfalls. Quant Imaging Med Surg. 2019;9(2):318-335. doi:10.21037/qims.2018.11.10

4. Yoshihara H. Sacroiliac joint pain after lumbar/lumbosacral fusion: current knowledge. Eur Spine J. 2012;21(9):1788-1796. doi:10.1007/ s00586-012-2350-8

5. Guentchev M, Preuss C, Rink R, Peter L, Wocker E-L, Tuettenberg J. Technical note: treatment of sacroiliac joint pain with peripheral nerve stimulation. Neuromodulation. 2015;18(5):392-396. doi:10.1111/ner.12255

6. Cher D, Polly D, Berven S. Sacroiliac joint pain: burden of disease. Med Devices. 2014;7(1):73-81. doi:10.2147/MDER.S59437

7. Maigne JY, Aivaliklis A, Pfefer F. Results of sacroiliac joint double block and value of sacroiliac pain provocation tests in 54 patients with low back pain. Spine (Phila Pa 1976). 1996;21:1889-1892. doi:10.1097/00007632-199608150-00012

8. Schuit D, McPoil TG, Mulesa P. Incidence of sacroiliac joint malalignment in leg length discrepancies. J Am Podiatr Med Assoc. 1989;79:380-383. doi:10.7547/87507315-79-8-380

9. Herzog W, Conway PJ. Gait analysis of sacroiliac joint patients. J Manipulative Physiol Ther. 1994;17:124-127.

10. Marymont JV, Lynch MA, Henning CE. Exercise-related stress reaction of the sacroiliac joint: an unusual cause of low back pain in athletes. Am J Sports Med. 1986;14:320-323. doi:10.1177/ 036354658601400414

11. Schoenberger M, Hellmich K. Sacroiliac dislocation and scoliosis. Hippokrates. 1964;35:476-479.

12. Albert H, Godskesen M, Westergaard J. Prognosis in four syndromes of pregnancy-related pelvic pain. Acta Obstet Gynecol Scand. 2001;80:505-510.

13. Berg G, Hammar M, Moller-Nielsen J, et al. Low back pain during pregnancy. Obstet Gynecol. 1988;71:71-75.

14. Katz V, Schofferman J, Reynolds J. The sacroiliac joint: a potential cause of pain after lumbar fusion to the sacrum. J Spinal Disord Tech. 2003;16:96-99. doi:10.1097/00024720200302000-00015

15. Cibulka MT, Sinacore DR, Cromer GS, Delitto A. Unilateral hip rotation range of motion asymmetry in patients with sacroiliac joint regional pain. Spine (Phila Pa 1976). 1998;23(9):1009-1015. doi:10.1097/00007632-199805010-00009

16. Krishnamoorthy V, Beck E, Kunze K, et al. Radiographic prevalence of sacroiliac joint abnormalities and clinical outcomes in patients with femoroacetabular impingement syndrome. Arthroscopy. 2019;35(9):2598-2605.e1. doi:10.1016/j.arthro.2019.03.030

17. Szadek KM, van der Wurff $P$, van Tulder MW, Zuurmond WW, Perez RSGM. Diagnostic validity of criteria for sacroiliac joint pain: a systematic review. J Pain. 2009;10(4):354-368. doi:10.1016/j.jpain.2008.09.014

18. Chou LH, Slipman CW, Bhagia SM, et al. Inciting events initiating injection-proven sacroiliac joint syndrome. Pain Med. 2004;5 (1):26-32. doi:10.1111/j.1526-4637.2004.04009.x

19. Telli H, Telli S, Topal M. The validity and reliability of provocation test in the diagnosis of sacroiliac joint dysfunction. Pain Physician. 2018;21:E367-E376. doi:10.36076/ppj.2018.4.E367

20. Barros G, McGrath L, Gelfenbeyn M, et al. Sacroiliac joint dysfunction in patients with low back pain. Federal Practitioner. 2019;36 (8):370-375.

21. Diekhoff T, Hermann KG, Greese J, et al. Comparison of MRI with radiography for detecting structural lesions of the sacroiliac joint using CT as standard of reference: results from the SIMACT study. Ann Rheum Dis. 2017;76:1502-1508. doi:10.1136/annrheumdis-2016-210640

22. Laplante BL, Ketchum JM, Saulio TR, et al. Multivariable analysis of the relationship. between pain referral patterns and the source of chronic low back pain. Pain Physician. 2012;15:171-178.
23. Merskey H, Bogduk N, eds. Classification of Chronic Pain: Descriptions of Chronic Pain Syndromes and Definitions of Pain Terms. 2nd ed. Seattle, WA: IASP Press; 1994.

24. Tuite M. Sacroiliac joint imaging. Semin Musculoskelet Radiol. 2008;12(1):72-82. doi:10.1055/s-2008-1067939

25. Guan F, Sun Y, Zhu L, et al. Risk factors of postoperative sacroiliac joint pain for posterior lumbar surgery: $\geq 2$-year follow-up Retrospective Study. World Neurosurg. 2017;107:789-794. doi:10.1016/j.wneu.2017.08.109

26. Dreyfuss P, Dreyer SJ, Cole A, Mayo K. Sacroiliac joint pain. $J$ Am Acad Orthop Surg. 2004;12(4):255-265. doi:10.5435/00124635200407000-00006

27. Murakami E, Tanaka Y, Aizawa T, Ishizuka M, Kokubun S. Effect of periarticular and intraarticular lidocaine injections for sacroiliac joint pain: prospective comparative study. J Orthop Sci. 2007;12 (3):274-280. doi:10.1007/s00776-007-1126-1

28. Polly DW, Cher DJ, Wine KD, et al.; INSITE Study Group. Randomized controlled trial of minimally invasive sacroiliac joint fusion using triangular titanium implants vs nonsurgical management for sacroiliac joint dysfunction: 12-month outcomes. Neurosurgery. 2015;77(5):674-690. doi:10.1227/NEU.0000000000000988

29. Polly DW, Swofford J, Whang PG, et al. Two-year outcomes from a randomized controlled trial of minimally invasive sacroiliac joint fusion vs. non-surgical management for sacroiliac joint dysfunction. Int J Spine Surg. 2016;10:28. doi:10.14444/3028

30. Cohen SP, Strassels SA, Kurihara C, et al. Outcome predictors for sacroiliac joint (lateral branch) radiofrequency denervation. Anesth Pain Med. 2009;34(3):206-214. doi:10.1097/AAP.0b013e3181958f4b

31. Dutta K, Dey S, Bhattacharyya P, et al. Comparison of efficacy of lateral branch pulsed radiofrequency denervation and intraarticular depot methylprednisolone injection for sacroiliac joint pain. Pain Physician. 2018;21:489-496.

32. Choi R, Deyo R, Friedly J, et al. Systemic pharmacologic therapies for low back pain: a systematic review for an American college of physicians clinical practice guideline. Ann Intern Med. 2017;166 (7):480-492. doi:10.7326/M16-2458

33. Chou R, Shekelle P, Qaseem A, Owens DK. Nonpharmacologic therapies for acute and chronic low back pain: a review of the evidence for an American pain society/American college of physicians clinical practice guideline. Ann Intern Med. 2008;148 (3):247-248. doi:10.7326/0003-4819-148-3-200802050-00020

34. Richardson CA, Snijders CJ, Hides JA, et al. The relation between the transversus abdominis muscles, sacroiliac joint mechanics, and low back pain. Spine. 2002;27(4):399-405. doi:10.1097/00007632200202150-00015

35. Mooney V, Pozos R, Vleeming A, et al. Exercise treatment for sacroiliac pain. Orthopedics. 2001;24(1):11199347. doi:10.3928/ 0147-7447-20010101-14

36. Zelle BA, Gruen GS, Brown S, George S. Sacroiliac joint dysfunction: evaluation and management. Clin J Pain. 2005;21(5):446-455. doi:10.1097/01.ajp.0000131413.07468.8e

37. Kennedy DJ MD, Engel A MD, Kreiner DS MD, et al. Fluoroscopically guided diagnostic and therapeutic intra-articular sacroiliac joint injections: a systematic review. Pain Med. 2015;16 (8):1500-1518. doi:10.1111/pme.12833

38. Maugars Y, Mathis C, Berthelot J-M, et al. Assessment of the efficacy of sacroiliac corticosteroid injections in spondylarthropathies: a Double-Blind Study. $\mathrm{Br} \quad J$ Rheumatol. 1996;35(8):767-770. doi:10.1093/rheumatology/35.8.767

39. Luukkainen R, Nissila M, Asikainen E, et al. Periarticular corticosteroid treatment of the sacroiliac joint in patients with seronegative spondyloarthropathy. Clin Exp Rheumatol. 1999;17(88-90):10084038.

40. Luukkainen R, Wennerstrand PV, Kautiainen HH, et al. Efficacy of periarticular corticosteroid treatment of the sacroiliac joint in non-spondyloarthropathic patients with chronic low back pain in the region of the sacroiliac joint. Clin Exp Rheumatol. 2002;20:52-54. 
41. Wendling D. Local sacroiliac injections in the treatment of spondyloarthritis. What is the evidence? Joint Bone Spine. 2020;87 (3):209-213. doi:10.1016/j.jbspin.2019.06.003

42. Braun J, Bollow M, Seyrekbasan F, et al. Computed tomography guided corticosteroid injection of the sacroiliac joint in patients with spondyloarthropathy with sacroiliitis. clinical outcome and followup by dynamic magnetic resonance imaging. $J$ Rheumatol. 1996;23:659-664.

43. Bollow M, Braun J, Taupitz M, et al. CT-guided intraarticular corticosteroid injection into the sacroiliac joints in patients with spondyloarthropathy. indication and follow-up with contrast-enhanced MRI. J Comput Assist Tomogr. 1996;20:512-521. doi:10.1097/00004728199607000-00002

44. Gunaydin I, Pereira PL, Daikeler T, et al. Magnetic resonance imaging guided corticosteroid injection of the sacroiliac joints in patients with therapy resistant spondyloarthropathy. a pilot study. J Rheumatol. 2000;27:424-428.

45. Pereira PL, Gunaydin I, Duda SH, et al. Corticosteroid injections of the sacroiliac joint during magnetic resonance. preliminary results. J Radiol. 2000;81:223-226.

46. Rosenberg JM, Quint DJ, de Rosayro AM. Computerized tomographic localization of clinically-guided sacroiliac joint injections. Clin J Pain. 2000;16(1):18-212000. doi:10.1097/00002508-200003000-00004

47. Ferrante FM, King LF, Roche EA, et al. Radiofrequency sacroiliac joint denervation for sacroiliac syndrome. Reg Anesth Pain Med. 2001;26(2):137-142200111251137. doi:10.1053/rapm.2001.21739

48. Ward S, Jenson M, Royal MA, et al. Fluoroscopy-guided sacroiliac joint injections with phenol ablation for persistent sacroiliitis: a case series. Pain Pract. 2002;2(4):332-335. doi:10.1046/j.15332500.2002.02043.x

49. Cohen SP, Abdi S. Lateral branch blocks as a treatment for sacroiliac joint pain.a pilot study. Reg Anesth Pain Med. 2003;28:113-119.

50. Buijs EJ, Kamphuis ET, Groen GJ. Radiofrequency treatment of sacroiliac joint-related pain aimed at the first three sacral dorsal rami: a minimal approach. Pain Clin. 2004;16(2):139-146. doi:10.1163/156856904774134334

51. Yin W, Willard F, Carreiro J, et al. Sensory stimulation-guided sacroiliac joint radiofrequency neurotomy: technique based on neuroanatomy of the dorsal sacral plexus. Spine. 2003;28 (20):2419-2425. doi:10.1097/01.BRS.0000085360.03758.C3

52. Kapural L, Nageeb F, Kapural M, et al. Cooled radiofrequency system for the treatment of chronic pain from sacroiliitis: the first case-series. Pain Pract. 2008;8(5):348-354. doi:10.1111/j.15332500.2008.00231.x

53. Burnham RS, Yasui Y. An alternate method of radiofrequency neurotomy of the sacroiliac joint. a pilot study of the effect of pain, function, and satisfaction. Reg Anesth Pain Med. 2007;32:12-19.

54. Roy JF, Hess M, Moissan C. MR guided cryosurgery of the sacroiliac joint. technique and early clinical results. Proc Intl Soc Mag Reson Med. 2001;9:2211.

55. Dreyfuss P, Snyder BD, Park K, et al. The ability of single site, single depth sacral lateral branch blocks to anesthetize the sacroiliac joint complex. Pain Med. 2008;9(7):18950439. doi:10.1111/j.15264637.2008.00517.x

56. King W, Ahmed SU, Baisden J, et al. Diagnosis and treatment of posterior sacroiliac complex pain: a systematic review with comprehensive analysis of the published data. Pain Med. 2015;16 (2):257-265. doi:10.1111/pme.12630

57. McKenzie-Brown AM, Shah RV, Sehgal N, Everett CR. A systematic review of sacroiliac joint interventions. Pain Physician. 2005;1:115-125.

58. Ferrante FM, King LF, Roche EA, et al. Radiofrequency sacroiliac joint denervation for sacroiliac syndrome. Reg Anesth Pain Med. 2001;26(2):137-142. doi:10.1053/rapm.2001.21739

59. Patil AA, Otto D, Raikar S. Peripheralnervefieldstimulation forsacroiliacjointpain. Neuromodulation. 2013;16:1.
60. Alo KM, Hirzallah M, Richter EO. Technical note: percutaneous cephalocaudal peripheral nerve stimulation for coccygodynia. J Neurosurg Rev. 2011;1(S1):78-81.

61. Buchowski JM, Kebaish KM, Sinkov V, Cohen DB, Sieber AN, Kostuik JP. Functional and radiographic outcome of sacroiliac arthrodesis for the disorders of the sacroiliac joint. Spine J. 2005;5 (5):520-528. doi:10.1016/j.spinee.2005.02.022

62. Dengler J MD, Kools D MD, Pflugmacher R MD, et al. Randomized trial of sacroiliac joint arthrodesis compared with conservative management for chronic low back pain attributed to the sacroiliac joint. J Bone Joint Surg. 2019;101(5):400-411. doi: 10.2106/JBJS.18.00022

63. Sturesson B, Kools D, Pflugmacher R, Gasbarrini A, Prestamburgo D, Dengler J. Six-month outcomes from a randomized controlled trial of minimally invasive SI joint fusion with triangular titanium implants vs conservative management. Eur Spine J. 2017;26(3):708-719. doi:10.1007/s00586-016-4599-9

64. Duhon BS, Bitan F, Lockstadt H, Kovalsky D, Cher D, Hillen T; SIFI Study Group. Triangular titanium implants for minimally invasive sacroiliac joint fusion: 2-year follow-up from a prospective multicenter trial. Int J Spine Surg. 2016;10:13. doi: $10.14444 / 3013$

65. Rudolf L. Sacroiliac joint arthrodesis-MIS technique with titanium implants: report of the first 50 patients and outcomes. Open Orthop J. 2012;6:495-502. doi:10.2174/1874325001206010495

66. Cummings JJr, Capobianco RA. Minimally invasive sacroiliac joint fusion: one-year outcomes in 18 patients. Ann Surg Innov Res. 2013;7 (1):12. doi:10.1186/1750-1164-7-12

67. Sachs D, Capobianco R, Cher D, et al. One-year outcomes after minimally invasive sacroiliac joint fusion with a series of triangular implants: a multicenter, patient-level analysis. Med Devices (Auckl). 2014;28(7):299-304.

68. Smith AG, Capobianco R, Cher D, et al. Open versus minimally invasive sacroiliac joint fusion: a multi-center comparison of perioperative measures and clinical outcomes. Ann Surg Innov Res. 2013;7 (1):14. doi:10.1186/1750-1164-7-14

69. Vanaclocha V, Herrera JM, Sáiz-Sapena N, Rivera-Paz M, VerdúLópez F. Minimally invasive sacroiliac joint fusion, radiofrequency denervation, and conservative management for sacroiliac joint pain: 6-year comparative case series. Neurosurgery. 2018;82(1):48-55. doi:10.1093/neuros/nyx 185

70. Dengler JD, Kools D, Pflugmacher R, et al. 1-year results of a randomized controlled trial of conservative management vs. minimally invasive surgical. Pain Physician 2017;20(6):537-550.

71. 360 Market Updates. Available from: https://www.360marketupdates. com/global-mis-sacroiliac-joint-fusion-market-13716161. Accessed November 24, 2020.

72. Smith-Petersen MN. Arthrodesis of the sacroiliac joint. A new method of approach. J Bone Joint Surg Am. 1921;3:400-405.

73. Lorio MP, Polly Jr. DW, Ninkovic I, et al. Utilization of minimally invasive surgical approach for sacroiliac joint fusion in surgeon population of ISASS and SMISS membership. Open Orthop J. 2014;8(1):1-6. doi:10.2174/1874325001408010001

74. iFuse Surgical Technique. Available from: https://si-bone.com/provi ders/ifuse/surgical-technique. Accessed November 24, 2020.

75. Schoell K, Buser Z, Jakoi A, et al. Postoperative complications in patients undergoing minimally invasive sacroiliac fusion. Spine J. 2016;16(11):1324-1332. doi:10.1016/j.spinee.2016.06.016

76. Duhon BS, Cher DJ, Wine KD, Lockstadt H, Kovalsky D, Soo CL. Safety and 6-month effectiveness of minimally invasive sacroiliac joint fusion: a prospective study. Med Devices (Auckl). 2013;6:219-229. doi:10.2147/MDER.S55197

77. Shamrock AG, Patel A, Alam M, Shamrock KH, Al Maaieh M. The safety profile of percutaneous minimally invasive sacroiliac joint fusion. Global Spine J. 2019;9:874-880. doi:10.1177/ 2192568218816981 
78. Martin CT, Haase L, Lender PA, Polly DW. Minimally invasive sacroiliac joint fusion: the current evidence. Int J Spine Surg. 2020;14:20-29. doi:10.14444/6072

79. Miller L, Block JE. Minimally invasive arthrodesis for chronic sacroiliac joint dysfunction using the SImmetry SI joint fusion system. Med Devices (Auckl). 2014;7:125-130. doi:10.2147/MDER. S63575

80. Frank RM, Slabaugh MA, Grumet RC, Virkus WW, Bush-Joseph CA, Nho SJ. Posterior hip pain in an athletic population: differential diagnosis and treatment options. Sports Health. 2010;2(3):237-246. doi:10.1177/1941738110366000
81. Bloski T, Pierson R. Endometriosis and chronic pelvic pain: unraveling the mystery behind this complex condition. Nurs Womens Health. 2008;12(5):382-395. doi:10.1111/j.1751-486X.2008.00362.x

82. Mellin G. Correlations of hip mobility with degree of back pain and lumbar spinal mobility in chronic low-back pain patients. Spine (Phila Pa 1976). 1988;13(6):668-670. doi:10.1097/00007632198813060-00012

83. Gómez-Hoyos J, Khoury A, Schröder R, Johnson E, Palmer IJ, Martin HD. The hip-spine effect: a biomechanical study of ischiofemoral impingement effect on lumbar facet joints. Arthroscopy. 2017;33(1):101-107. doi:10.1016/j.arthro.2016.06.029

\section{Publish your work in this journal}

The Journal of Pain Research is an international, peer reviewed, open access, online journal that welcomes laboratory and clinical findings in the fields of pain research and the prevention and management of pain. Original research, reviews, symposium reports, hypothesis formation and commentaries are all considered for publication. The manuscript management system is completely online and includes a very quick and fair peer-review system, which is all easy to use. Visit http:// www.dovepress.com/testimonials.php to read real quotes from published authors. 